\title{
The Impact of Institutional Environment on Entrepreneurship Post-COVID 19
}

\author{
Inga Davids-Van Wyk ${ }^{1} \quad$ Gregory Davids $^{2 *} \quad$ Nicolette Roman $^{3}$ \\ 1. Inga Davids - Business Consultant-Masters Business Management Graduate - Brunel University \\ 2. Gregory Davids -School of Government ( University Western Cape) Robert Sobukwe Avenue, \\ Bellville Cape Town South Africa \\ 3. Nicolette Roman- Faculty of Community. And Health Sciences, University Western Cape
}

\begin{abstract}
The COVID 19 pandemic and subsequent lockdown left in its wake a world -wide socio-economic disaster. Small medium and micro-enterprises (SMME) on the African continent were pushed into financial distress and many facing financial ruin and bankruptcy. The partial relaxation of the hard lockdown was aimed at achieving a balancing act between savings people's lives and averting a socio-economic disaster. Entrepreneurship is key and hold the answer to kick start the economy ensuring economic growth, prosperity, employment creation and ultimately poverty reduction (Klapper, Laeven and Rajan. 2006). It is a known fact that not all entrepreneurs are equally successful in their endeavors. This paper is a review and synthesis of the literature in an attempt to understand in what way, if any, the institutional environment impact on entrepreneurship. A desktop study was used to do a literature review from six journals covering the period 2013-2018. The findings indicated that a number of factors such as liability of newness impact on entrepreneurship. The findings are important to understand the impact of institutional environment on entrepreneurial survival and how to respond during a crisis such as COVID 19.
\end{abstract}

Keywords: Institutional Environment , Institutional theory, Emerging economies, Institutional and entrepreneurship, Entrepreneur, SMME

DOI: $10.7176 / \mathrm{EJBM} / 12-33-05$

Publication date: November $30^{\text {th }} 2020$

\section{Introduction}

The Covid 19 pandemic plunged the world in an economic and social turmoil and disrupted the normal pattern of life. The international health pandemic left in its wake a wave of destruction, destroying people's livelihoods and plunging many into poverty and despair. Governments introduced measures to fight the pandemic resulting in their economies grinding to a halt. Small medium and micro-enterprises (SMME) overnight pushed into financial distress and many facing financial ruin and bankruptcy. Small medium and micro enterprises on the African continent is a key sector in employment creation and contributing to the gross domestic product. The Covid 19 hard lockdown resulted in unplanned business closure and many filings for bankruptcy. The collapse of the SMME sector hold dire consequences for many employed in the sector and could exacerbate the triple challenges of unemployment, poverty and inequality. Entrepreneurship holds the answer to kick start the economy and is key to the SMME development, economic growth, prosperity, employment creation and ultimately poverty reduction (Klapper, Laeven and Rajan. 2006). It is a known fact that not all entrepreneurs are equally successful in their endeavors. Many factors contribute thereto and one such factor is the impact of the institutional environment on entrepreneurship. Given the current crises and possible collapse of the SMME sector it is important to understand the relationship of the institutional environment on successful entrepreneurship. Researchers such as Autio and Fu (2014), Chowdhury, Audretsch and Belitski, (2016) and Bosma, Sanders, Stam and Content, (2018) investigated the relationship between the institutional environment and entrepreneurship in various contexts. On the one-hand scholars identified that institutional environments shape entrepreneurship and on the other hand other scholars recognised that entrepreneurs have the ability to shape institutional environments (Bosma et al., 2018; Bylund and McCaffrey, 2017). This suggests a possible symbiotic relationship between institutions and entrepreneurs.

A review and synthesis of this body of research is important as it highlights how the institutional environment may define, support or constrain aspects of entrepreneurship (Chowdhury, Audretsch and Belitski, 2016; Urbano \& Alvarez, 2014). This paper is a review and synthesis of the literature in an attempt to understand in what way, if any, the institutional environment impact on entrepreneurship.

\section{Methodology}

A desktop study using a longitudinal literature review was done covering the period 2013-2018. The paper primarily reviewed the literature from six journals to ensure the credibility of the data collection process (Webster and Watson, 2002). The decision to use the six journals was based on the 2015, Academic Journal Guide. The journals reviewed according to the Academic Journal Guide is considered top ranking in the respective fields (i.e. entrepreneurship, international business and economics). 
The list of journals included four entrepreneurship journals (Entrepreneurship: Theory and Practice (ETP), Journal of Business Venturing (JBV), Small Business Economics (SBE), Journal of International Entrepreneurship), an international business journal (Asia Pacific Journal of Management (APJM)) and an economic journal (Review of Development Economics (Rev. Dev. Econ.). In the search for the appropriate literature, the following databases were also used: Business Source Premier and Emerald Insight. The prestigious databases hold a portfolio of articles from renowned journals covering major disciplines, which ensured credible articles to be retrieved and possibly referenced.

Searches in the relevant journals and databases were conducted with the aim of discovering articles that examined the relationship between institutions and entrepreneurship over the 2013-2018 period. A set of criteria was used to conduct a focus research with the aim to establish which articles to include and which articles to exclude (Randolph, 2009). The following keywords were included and used "institutions", "institution type", "institutional theory", "emerging economies", "institutional environment" combined with "entrepreneurship", "entrepreneur", "entrepreneurial activity" and "entrepreneurial growth".

Relevant articles where analyse to answer the research question and needed to have a substantial focus on the institutional environments. Particular emphasis was placed on the types and dimensions of institutional environments that impact aspects of entrepreneurship such entrepreneurial motives, entrepreneurial activities and quality of entrepreneurship.

To assess the relevance of the articles, each of the articles was examined by reviewing the abstract, introduction, conclusion and in some cases other sections of the paper as well. Furthermore, a browse of the reference section was conducted as a means to discover additional relevant articles that may have been cited across multiple articles. Articles that were deemed relevant were read in entirety to understand the progression of research questions, methodology, central results and implications for academia and practitioners. After reviewing the articles, approximately 15 academic articles were identified to best fit the objective of the study and are referenced in the literature review.

In addition to the review of the latest academic research, classical work of North (1990) and Scott (Mayntz, 1996) was examined to gain an understanding of the underlying institutional and entrepreneurship research. Where an electronic source was not available, a hard copy was retrieved from the library or a book review examined.

\section{Results}

The literature over the last five years (2013-2018) extensively explored the link between the institutional environment and entrepreneurship from varying angles. For example, scholars such as Bosma, Content and Sanders (2018) and Urbano \& Alvarez(2014) analysed how the holistic institutional environment may impact the probability of becoming an entrepreneur. In contrast, other scholars such as Autio and Fu, (2014), Stenholm, Acs and Wuebker, (2013) Dau and Cuervo-Cazurra, (2014) had granular research questions such as how specific dimensions of an institutional environment may encourage and facilitate various entrepreneurial activities (e.g. formal vs. informal entrepreneurship and opportunity-driven vs. necessity-driven entrepreneurship). Autio and Fu (2014) say that the quality of the institution has a substantial influence on both formal and informal entrepreneurship. According to them an increase in the quality of economic and political institutions could double the rates of formal entrepreneurship and halve the rate of informal entrepreneurship. These examples indicate that a portion of the research has isolated aspects of the theories to test the varying hypothesis. In addition, the varying research questions may provide an indication of the complex relationship between the institutional environment and entrepreneurship.

The research questions were underpinned by varying theories. Most of the research continues to cite the seminal work of North (1990) and Scott (Mayntz,1996) as a foundation for examining the research hypothesis. More than ten of the articles included in the literature review based the research on institutional theory. Institutional theory recognises North's (1990) theory of 'institutions. He put forward the idea that institutions are characterised by formal (i.e. rules, regulations, policies) and informal constraints (i.e. norms, values, perceptions) (Chowdhury, Audretsch and Belitski, 2016; North, 1990; Urbano \& Alvarez, 2014). Furthermore, the research also referenced Scott's (Mayntz,996) work regarding the dimensions of the institutional environment (i.e. regulatory, cognitive and normative dimensions) (Sambharya and Musteen, 2014).

Although these theories may be different, it provides a framework to understand the varying degrees in which institutions may influence the behaviours of the actors in a given environment. Furthermore, the different theories may also suggest that institutions cannot be considered in isolation of the social forces of an environment. In addition, the continued use of the seminal work may be an indication of how useful institutional theory has been in the entrepreneurship field. To explore the research objectives scholars established a methodology to test the hypothesis deciding on the sample characteristics and data analysis approach.

The literature review revealed that different methodologies were used to test the hypotheses. The sample characteristics of the papers included a subset of countries and examined the data over specified time horizons. The majority of the research examined institutional environments and its impact on different aspects of 
entrepreneurship over a specific time horizon. Often the time horizons did not exceed more than 10 years. According to Estrin, Korosteleva and Mickiewicz (2013), the time horizons of the datasets were not long enough to sufficiently test the impact of institutional environments on entrepreneurship. Future research may want to explore the relationship between institutional environments and entrepreneurship over longer time horizons. In addition, more than eight of the researchers used a combination of Global Entrepreneurship Monitor (GEM) and World Bank data to test the research hypothesis (Autio and Fu, 2014; Stenholm, Acs and Wuebker, 2013; Urbano, Aparicio and Audretsch, 2018). While this dataset does provide a comprehensive cross-country dataset, it is limited in the number of countries as well as its inclusion of developing countries (Autio and Fu, 2014; Estrin, Korosteleva and Mickiewicz, 2013). Therefore, the research does not necessarily give a balanced view of how the theories impact a diverse body of institutional environments. Future researchers may want to address these limitations by testing the established theories against different contexts.

\section{Findings and Discussion}

The findings across the literature were extensive. This was due to the increased interest in the topic over the year as scholars examined the impact of institutional environments on entrepreneurship from different perspectives (Urbano and Alvarez, 2014). The research recognised that institutions govern the organisations or individuals of the environment (Chowdhury, Audretsch and Belitski, 2016; Bosman, Content and Sanders, 2018). In addition, the literature acknowledged that entrepreneurs are the individuals or actors in the institutional environment under examination (Carlson et al. 2013). Furthermore, entrepreneurship was recognized as the formation of new business ventures that drive economic growth and development (Carlsson et al., 2013; Bosman, Content and Sanders, 2018). Therefore, the research findings explained how the institutional environment influences various factors of entrepreneurship. In addition, the literature highlighted that institutional environments (e.g. rules, culture, skills) are multi-faceted and can define, support or restrict aspects of entrepreneurship (Chowdhury, Audretsch and Belitski, 2016; Estrin, Korosteleva and Mickiewicz, 2013; Urbano and Alvarez, 2014). At a more granular level, the literature highlighted common themes in respect to the findings. The common themes identified included the factors that influenced the entrepreneur's decision to enter a market, the entrepreneurial activities pursued and finally the liability of newness. The sections that follow detail each of these themes.

\section{Decision to start a business}

The first common finding related to how institutional environments may impact prospective entrepreneurs' decision to start new ventures or not (Bosma, Content and Sanders, 2018; Urbano \& Alvarez, 2014). This is important to understand because to achieve a degree of success, entrepreneurs must evaluate the markets and environment that they plan to enter (Kirkley, 2016). Institutional theory was used in the literature to explain why entrepreneurs choose to start new ventures, frequently highlighting the favorable and unfavorable dimensions (i.e. regulatory, cognitive and normative) of the institutional environment that may influence this decision (Bosma, Content and Sanders, 2018; Urbano \& Alvarez, 2014).

The literature reviewed highlighted that the different dimensions of the institutional environment such as the regulatory (i.e. laws, regulations and policies), normative (i.e. values and beliefs) and cognitive (i.e. education, skills possessed by individuals) dimensions may either increase or decrease the probability of an individual's choice to become an entrepreneur (Bosma, Content and Sanders, 2018; Urbano \& Alvarez, 2014). For example, institutional environments that have a substantial pool of skills and knowledge, referred to as the cognitive dimension, may result in an increased probability of entrepreneurship.

In contrast, unfavorable regulatory institutional environments characterised by hefty license fees and possible delays to issue the license result in a prospective entrepreneur not entering the market (Bennet and Estrin, 2013; Urbano and Alvarez, 2014). This example illustrates how an unfavorable dimension of an institutional environment may caution an entrepreneur to enter a market. Consequently, this unfavorable dimension may decrease that individual's probability of becoming an entrepreneur and subsequently negatively influence entrepreneurial growth. This is an important finding for policy makers to review their policies and remove those restrictive measures that impedes entrepreneurship. The establishment of an enabling regulatory environment is dependent on the removal of the restrictive red tape and the establishment of a responsive regulatory authority.

\section{Relationship between institutional environment and Types of business venture}

A second theme analysed was how the institutional environments influences the types of business ventures pursued. The entrepreneurial activity pursued is often linked to the conditions (e.g. strict regulations, barriers to entry and poverty) of an institutional environment. The institutional environment influences the type of entrepreneurial business created (Dau and Cuervo-Cazurra, 2014; Autio and Fu, 2014). This stream of research extended the understanding of the relationship between the institutional environment and entrepreneurship. In support of exploring this idea, Autio and Fu (2014) found that an institutional environment has a significant impact on the form of entrepreneurial activities, either giving rise to formal (i.e. registered businesses) or informal (i.e. non- 
registered businesses) entrepreneurship. For example, institutional environments that have onerous business regulations may give rise to informal entrepreneurship, as individuals may want to circumnavigate the rules and fees associated with registering a business. In contrast, Dau and Cuervo-Cazurra $(2014 ; 670)$ suggested that "a reduction in the government's direct intervention in the economic arena", which the authors labelled as economic liberalization, supports both informal and formal entrepreneurship.

Dau and Cuervo-Cazurra (2014) suggested that economic liberalization encourages overall business creation, therefore, lessening barriers to entry and driving holistic economic growth. In addition, some scholars examined additional entrepreneurial activities that the institutional environment may encourage. For example, Sambharya and Musteen (2014) considered factors of the institutional environment that facilitated either opportunity-driven (i.e. individuals who voluntarily identify and execute feasible business ideas) or necessity-driven (i.e. individuals forced to enter entrepreneurship due to lack of employment options) entrepreneurship. It is important to recognise these nuances as the different activities can either have productive or unproductive effects on the economy (Dau and Cuervo-Cazurra, 2014).

\section{Overcoming liability of newness}

The third theme that the review of the literature revealed is overcoming the liability of newness. The concept "liability of newness" according to Abatecola, Cafferata and Poggesi (2012) was first introduced by Stinchcombe in 1965 and he explained why organizations tend to fail within the earliest stages of their life cycle

De Vaughn and Leary, 2018; Williams, Martinez-Perez and Kedir, (2017) focus on aspects of the institutional environment and the relationship in overcoming the liability of newness. By testing this hypothesis, the researchers broadened the understanding of whether enterprises that delay registration of new ventures (i.e. informal ventures) truly are worse off than businesses that decide to register upfront (i.e. formal ventures). The research to date hypothesised that registered ventures outperform non-registered firms due to the fact that registered businesses enjoy better markets, stronger links with stakeholders and access to established financing networks than unregistered business. Williams, Martinez-Perez and Kedir (2017) though found that new ventures that delayed registration outperformed businesses that registered upfront. In addition, the research suggested that the outperformance was due to non-registered firms devoting more resources to reduce inefficiencies, build relationships with suppliers and team members rather than using resources to ensure successful registration (Williams, Martinez-Perez and Kedir, 2017).

Therefore, this body of research questioned whether non-registration results in lack of business legitimacy, which influences the business' liability of newness (Williams, Martinez-Perez and Kedir, 2017). The problem though with non-registration is that it limits the SMME's ability to take advantage of business opportunities with formally registered business or the public sector. Importantly non-registration inhibits the SMME to access startup capital to sustain them during this period. The non-registration advantage is short term but is counterproductive for sustainable growth.

Recent research suggested that policy regulations of an institutional environment do not necessarily protect new firms from the impacts of liability of newness but rather merely delay the impact. DE Vaughn and Leary (2018) found that in the short term, policies could aid SMME's to reduce the liability of newness. These policies amongst other could be taxation holidays or government support for SMME development. However, over-time these policies supported must be combined with other institutional factors to ensure the continued growth of new ventures. If not, these start-ups will suffer the fate of newness and fail.

\section{Conclusions}

The study highlighted the varying aspects of the institutional environment and its impact on an entrepreneur's decision to enter a market, the entrepreneurial activities pursued and finally overcoming the liability of newness. Consequently, the body of research has implications for entrepreneurs and policymakers. The research raises awareness for prospective entrepreneurs when assessing the conditions that may be in favor of starting a new venture as well as the limitations that institutional environments may impose. For current entrepreneurs, the research provides insights into understanding how the changing dimensions of institutions may impact venture growth. As mentioned previously there were limitations in the methodologies that supported the research. These limitations extended to the number of countries included in the sample and the short time horizons to name a few. Even though there were limitations in the studies, the literature recognised that institutions influence entrepreneurship, which may impact the economic growth and development of a nation. Therefore, future studies may seek to include how issues such as social well-being, gender equality or alleviation of poverty may influence the decision to start new business ventures. This may extend the body of knowledge beyond just economic reasons for institutions to facilitate and support entrepreneurship (Bosma et al., 2018; Urbano, Aparicio and Audretsch,2018). Entrepreneurship hold the answer to kick start and grow the economy and prevent a major human catastrophe. The article contributed to the discourse on how to restart the economy post COVID19 and in particular the importance of the institutional environment with regard to entrepreneurship. 


\section{References}

Abatecola G., Cafferata R., Poggesi S. (2012), Arthur Stinchcombe's "liability of newness". Contribution and impact of the construct. Journal of Management History, 18 (4): 402-418.

Autio, E. and $\mathrm{Fu}, \mathrm{K}$. (2015) 'Economic and political institutions and entry into formal and informal entrepreneurship', Asia Pacific Journal of Management, 32(1), pp. 67-94.

Bennett, J. and Estrin, S. (2013) 'Regulatory Barriers and Entry into a New Competitive Industry', Review of Development Economics, 17(4), pp. 685-698. doi: 10.1111/rode.12059.

Bosma, N., Sanders, M., Stam, E. and Jeroen Content (2018) 'Institutions, entrepreneurship, and economic growth in Europe', Small Business Economics, 51(2), pp. 483-499.

Bylund, P.L. and McCaffrey, M. (2017) 'A theory of entrepreneurship and institutional uncertainty', Journal of Business Venturing, 32(5), pp. 461-475.

Carlsson, B., Braunerhjelm, P., McKelvey, M., Olofsson, C., Persson, L. and Ylinenp, H. (2013) 'The evolving domain of entrepreneurship research', Small Business Economics, 41(4), pp. 913-930.

Dau, L.A. and Cuervo-Cazurra, A. (2014) 'To formalize or not to formalize: Entrepreneurship and pro-market institutions', Journal of Business Venturing, 29(5), pp. 668-686.

De Vaughn, M. L. and Leary, M. M. (2018) 'Learn by Doing or Learn by Failing? The Paradoxical Effect of Public Policy in Averting the Liability of Newness', Group \& Organization Management, 43(6), pp. 871-905. doi: $10.1177 / 1059601116674826$.

Estrin, S., Korosteleva, J. and Mickiewicz, T. (2013) 'Which institutions encourage entrepreneurial growth aspirations?', Journal of business venturing, 28(4), pp. 564-580.

Kirkley, W.W. (2016) 'Creating ventures: decision factors in new venture creation', Asia Pcfc Jrnl Innvtn \& Entrprnshp, 10(1), pp. 151-167. doi: 10.1108/APJIE-12-2016-003.

Klapper,L Laeven,L, Rajan,R. Entry regulation as a barrier to entrepreneurship Journal of Financial Economics · Volume 82, Issue 3, December 2006, Pages 591-629

Mayntz, R. (1996). Book Reviews: W. Richard Scott: Institutions and Organizations 1995, Thousand Oaks, London, New Delhi: Sage. 178 pages. Organization Studies, 17(3), 539-541. https://doi.org/10.1177/017084069601700309

Randolph, J.J. (2009) 'A guide to writing the dissertation literature review', Practical Assessment, Research \& Evaluation, 14(13), pp. 1-13.

Sambharya, R. and Musteen, M. (2014) 'Institutional environment and entrepreneurship: an empirical study across countries', Journal of International Entrepreneurship, 12(4), pp. 314-330.

Stenholm, P., Acs, Z.J. and Wuebker, R. (2013) 'Exploring country-level institutional arrangements on the rate and type of entrepreneurial activity', Journal of Business Venturing, 28(1), pp. 176-193.

Urbano, D. and Alvarez, C. (2014) 'Institutional dimensions and entrepreneurial activity: an international study', Small Business Economics, 42(4), pp. 703-716.

Urbano, D., Aparicio, S. and Audretsch, D. (2018) 'Twenty-five years of research on institutions, entrepreneurship, and economic growth: what has been learned?', Small Business Economics, pp. 1-29.

Webster, J. and Watson, R.T. (2002) 'Analyzing the past to prepare for the future: Writing a literature review', MIS quarterly, 26(2), pp. xiii-xxiii

William J. Baumol (1990) 'Entrepreneurship: Productive, Unproductive, and Destructive', Journal of Political Economy, 98(5), pp. 893-921.

Williams, C.C., Martinez-Perez, A. and Kedir, A.M. (2017) 'Informal Entrepreneurship in Developing Economies: The Impacts of Starting up Unregistered on firm Performance', Entrepreneurship Theory and Practice, 41(5), pp. 773-799. doi: 10.1111/etap.12238. 